\title{
Benedetta Belloni y
}

Francesca Crippa

ENTREVISTAN A

\section{Ángel de la Calle}

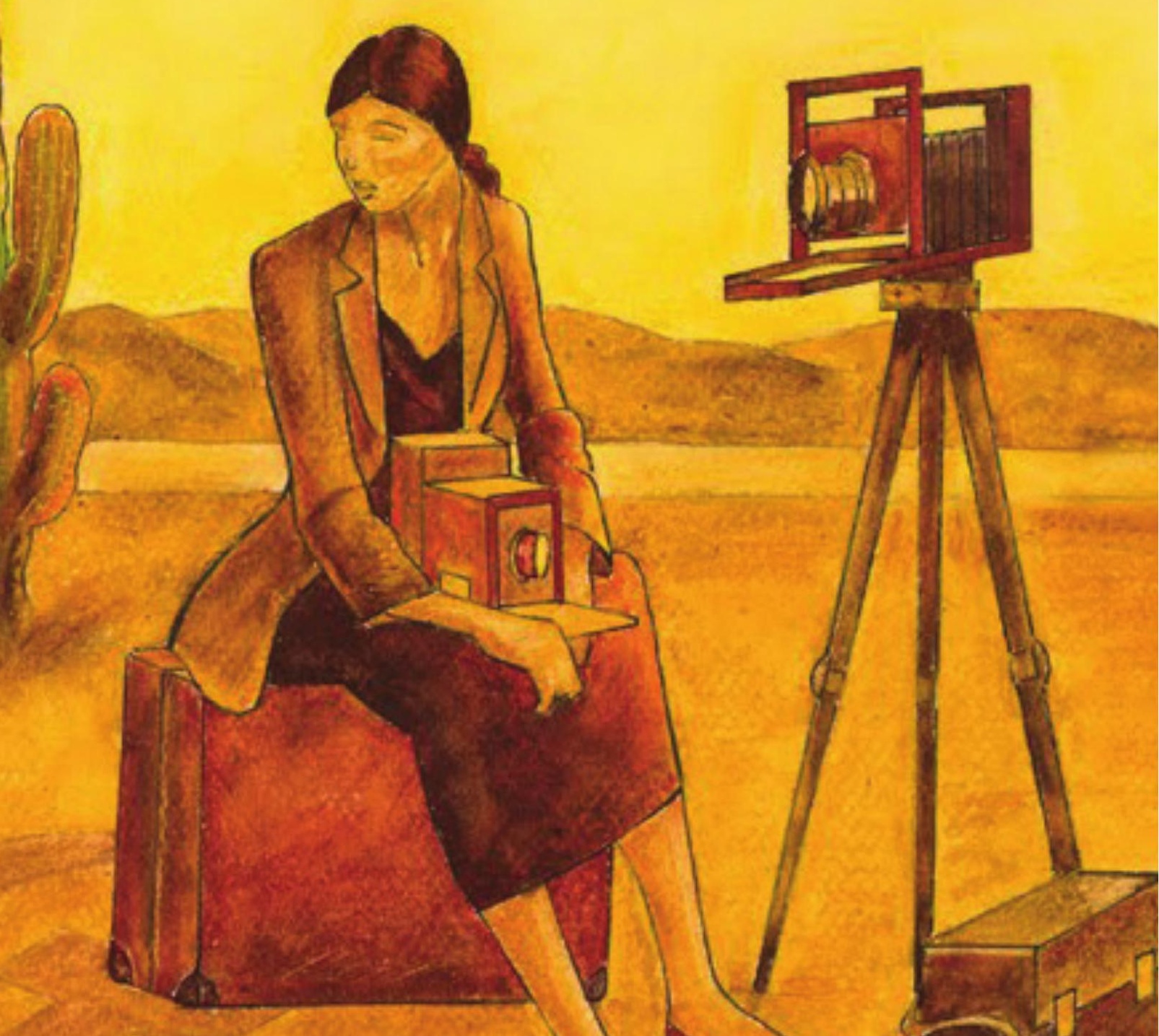




\section{El lenguaje del cómic en el contexto cultural español contemporáneo}

Ángel de la Calle (Molinillo de la Sierra, 1958) es un historietista, guionista, diseñador e ilustrador atípico, de obra cambiante, comprometida y singular. ${ }^{1}$ Nace en un pequeño pueblo de la provincia salmantina pero pronto su familia se traslada a Gijón, ciudad en la que vive desde entonces. Se inicia en la historieta durante la década de los setenta, más precisamente en los inicios del boom del cómic adulto en España, y publica sus primeros dibujos no remunerados en las revistas del Partido Comunista español. Sucesivamente, empieza a dedicarse al cartelismo y a publicaciones marginales para pasar luego a colaborar con importantes revistas nacionales: Star, Bésame Mucho, Rambla, Rampa-Rambla, Zona 84, Comix Internacional, El Vibora. ${ }^{2}$ Colabora también con revistas foráneas: la sueca Tung Metal, la francesa Fantastik y la estadounidense Heavy Metal. En 1988 participa en la organización de la Semana Negra de Gijón, festival literario y

\footnotetext{
1 En algunos casos, el autor ha firmado sus obras con el pseudónimo Adela C.

2 La colaboración con las revistas mencionadas empieza en los años setenta y sigue a lo largo de la década de los ochenta.
}

cultural que dirige, en sus contenidos, desde 2012. Desde 1989 es también director del periódico A quemarropa, editado por la misma Semana Negra.

Hacia finales de los noventa empieza a dedicarse a la realización de storyboards para publicidad y para la película de Gonzalo Suárez titulada El lado oscuro (1991). En 1996, bajo el seudónimo Adela C., crea la tira «Mary Mari» para los diarios La Nueva España (la primera temporada) y El Comercio (a partir de la segunda): esta tira diaria se publica desde entonces durante los meses de verano de cada año.

En el nuevo siglo siente la necesidad de crear historietas más ambiciosas. En 2002, ilustra la novela corta de Paco Ignacio Taibo II, Mon ami Morán. Al año siguiente aparece la primera parte de una obra muy amplia: Modotti. Una mujer del siglo XX, la biografía de la fotógrafa y activista política italiana Tina Modotti (1896-1942), que se completa en un segundo tomo en 2005. Con este libro, traducido a cinco idiomas, gana el Premio de la Crítica en 2006. Los dos volúmenes son recogidos en la obra integral edi- 
tada en el año 2007. Ese mismo año publica el libro de reflexión teórica Hugo Pratt: la mano de Dios y, en 2008, El hombre enmascarado: en el sendero. Inicia también su serie autobiográfica Diarios de festival de la que han salido dos episodios. Durante 2016 aparecerá su segunda novela gráfica de largo aliento titulada Pinturas de guerra, un recorrido por el exilio latinoamericano de los años setenta y el arte contemporáneo comprometido. De la Calle ha sido codirector de la revista de análisis de cómic Dentro de la Viñeta (32 números publicados) y es codirector y creador de las Jornadas Internacionales del Cómic Villa de Avilés.

Con motivo de la celebración de una de las conferencias del ciclo Palabras Contemporáneas, organizado por el prof. Dante Liano en la Universidad Católica del Sacro Cuore de Milán en colaboración con el Instituto Cervantes, Benedetta Belloni y Francesca Crippa entrevistaron al autor. ${ }^{3}$

\section{¿Cómo empezó tu carrera de dibujante/ autor de cómic?}

Antes de saber leer y hablar correctamente ya «leía» cómic. Acostumbro a decir que el lenguaje de los cómics es mi lengua materna. A los diecisiete años hice mi primer fanzine y a los diecinueve publiqué profesionalmente por primera vez (profesionalmente quiere decir aquí cobrando) en la revista Star. Después, en las revistas españolas de la época: $E l$ Vibora, Rambla, Comix Internacional, Zona 84, la norteamericana Heavy Metal, etc. En los años setenta del siglo pasado no había escuelas de cómic, todos éramos autodidactas.

\section{¿Cómo surgen tus novelas, cómo eliges los temas y las historias que decides contar?}

\footnotetext{
3 La entrevista se realizó el día 17 de marzo de 2016.
}

\section{¿Adaptas el estilo de tus dibujos al tema que tratas?}

No sé, mis historias normalmente aparecen por ahí... En el caso de la última, la que no ha salido todavía, Pinturas de guerra, la idea surgió de un viaje que hice a Buenos Aires, cuando me llevaron a la Plaza de Mayo, que es uno de los símbolos de la ciudad. Ahí pude asistir a una manifestación de las madres delante de la Casa Rosada, lo que me hizo reflexionar sobre temas importantes como la moral y el espíritu de solidaridad. En Pinturas de guerra, pues, mis personajes son pintores guerrilleros latinoamericanos de los años setenta que ganaron el futuro y perdieron el presente: un uruguayo tupamaro, un argentino montonero, una chilena mirista y un mexicano exiliado en París. En la novela, por lo tanto, decidí mezclar la historia con el arte contemporáneo, que es algo que me gusta hacer. Como hice también en el caso de Modotti. La idea de escribir una novela gráfica sobre la fotógrafa surgió mientras estaba viviendo en Ciudad de México, una ciudad muy importante para ella. Ahí descubrí la historia de esa mujer gracias a la lectura de las memorias de Pablo Neruda (Confieso que he vivido, 1974) en las que Modotti aparece retratada como un personaje clave en la historia cultural del siglo xx: fotógrafa políticamente comprometida, actriz en Hollywood, modelo para el artista norteamericano Edward Weston, heroína durante la guerra civil española y gran amiga de intelectuales como Diego Rivera, Antonio Machado y Sergei Eisenstein.

\section{¿Cuáles son las técnicas que manejas para dibujar tus historias?}

Desde mi perspectiva, el lenguaje del cómic es un instrumento maravilloso que permite alcanzar diferentes objetivos. De hecho, 

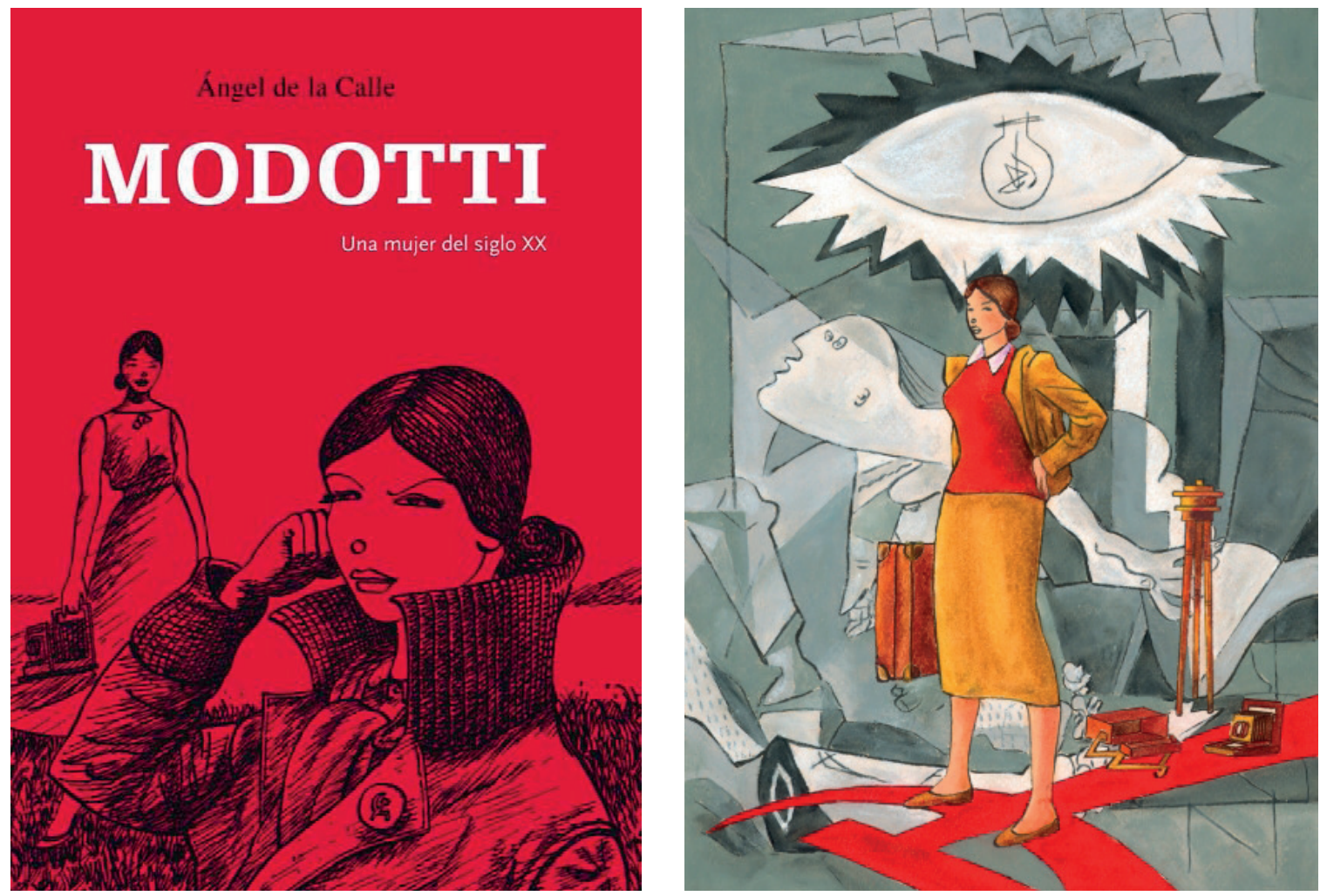

Portadas de la edición española y portuguesa de la novela Modotti. Una mujer del siglo xx.

se basa en la fusión entre las técnicas de la narrativa tradicional, que existen desde hace siglos, y las novedades de la representación gráfica, inspiradas por los principales movimientos artísticos. En el caso de Modotti, por ejemplo, la definición de novela gráfica es reductiva porque en realidad yo he conseguido producir un texto híbrido que es, por un lado, un ensayo novelesco ilustrado y, por otro, la historia del pensamiento de izquierda a lo largo de la primera mitad del siglo xx.

\section{¿Reconoces temas tópicos en las novelas} gráficas contemporáneas? ¿Qué opinas, en particular, del tratamiento de asuntos delicados como guerras, conflictos, crisis, etc.?

Desde siempre, el conflicto genera historias y sin embargo es muy difícil escribir una historia sobre el conflicto. Contar la historia es necesario, pero el éxito de una obra depende también de la habilidad del autor en contarla. Algunos temas se adaptan mejor a ser narrados mientras que otros, sobre todo los filosóficos, se escapan a las técnicas tradicionales de la escritura. Yo he tratado el tema del conflicto más importante para la reciente historia española, es decir, la guerra civil, en una de mis historietas titulada «Entre líneas», que se publicó en 2006 en la miscelánea Nuestra Guerra Civil. El volumen presenta un fuerte compromiso político, lo que implica que el tema de la guerra todavía no está solucionado y que los historietistas españoles siguen percibiendo el deber generacional de la memoria que se manifiesta en la atención hacia cuestiones pasadas pero candentes en la costrucción de la identidad nacional actual.

Desde mi punto de vista, sin embargo, la novela gráfica contemporánea se juega más 



Primera página de la historieta «Entre líneas» (Nuestra Guerra Civil, Ariadna Editorial, 2006). Imagen por cortesía del autor. 
en la estructura que en los temas, porque es la estructura lo que hace la diferencia. El lenguaje del cómic tiene la ventaja de crear una dinámica narrativa en la que el lector se reconoce como parte de un sistema que le invita a seguir leyendo.

¿Existe un público experto de cómic o de novela gráfica? ¿Los lectores de novelas «tradicionales» son también lectores de cómics?

Yo creo que todos los géneros están muy bien interconectados. Desde mi punto de vista, el lector ideal de cómic es también lector de novelas. Sin embargo, hay un lector maravilloso para cualquier género que es el lector adolescente. A los adolescentes hay que guiarlos porque serán lectores para toda su vida. En algunos casos, mis textos se dirigen a lectores más cultos que sepan reconocer las referencias intertextuales que suelo colocar dentro de mis historias. En Modotti, por ejemplo, hago referencia a Walter Benjamin y también a Ernest Hemingway. Los escritores andamos buscando al lector ideal $y$, sin embargo, el lector ideal es el que lee tu libro y luego empieza a documentarse sobre la historia y siente la necesidad de profundizar las informaciones.

¿Crees que la novela gráfica sigue siendo considerada «inferior" con respecto a las novelas tradicionales? ¿Hay todavía prejuicios sobre el género? ¿Qué elementos ulteriores aporta a una historia la novela gráfica con respecto a una novela tradicional?

Algunos aún tienen prejuicios con este lenguaje mestizo, donde los dibujos se leen y las palabras se dibujan, pero no creo que sea un problema de lenguaje. Más bien de que, al haber estado enfocado hacia el público infantil o adolescente, las obras han sido en su gran mayoría muy flojas y poco cultas o cultivadas, con un gran desarrollo en la parte gráfica y mucho menos en los temas y las narrativas. Desde hace quince años los temas y las formas de narrar se han desarrollado tanto que no creo que haya asuntos que trate la novela y que no trate la novela gráfica. Otra cosa es que el mercado actual de cualquier tipo de producto cultural (más bien de ocio) tenga como meta el lector, el consumidor, adolescente. Pero ese es un mal de todos los medios de comunicación, artísticos o no, desde que el neoliberalismo es el pensamiento único. Por eso la mayor parte de las novelas y las novelas gráficas tienen un único fin: vender. Cuanto más, mejor. Pero en este campo de las viñetas, como en cualquier otro, si se sabe buscar se encuentran perlas narrativas por las que merece la pena buscar.

¿Qué opinas del éxito del que está actualmente gozando la novela gráfica sobre todo en España (congresos dedicados, jornadas de estudio, expertos universitarios del tema, revistas especializadas, etc.)?

¿Cómo se consigue el derecho a la huelga? Haciendo huelga. No hay otra forma de conseguirlo. Pues, esto es igual. Gracias a los estudios que se están realizando sobre cómic y novela gráfica, el género está ganando cada día más importancia. Como decía Bourdieu, se ha creado un campo cultural porque hay autores y editores y actividades que dan prestigio y reconocimiento. Podemos afirmar que se ha creado un campo cultural del cómic o de la novela gráfica que tiene todo lo que tienen los demás campos culturales. Será labor de los que están en este ámbito seguir ampliándolo.

¿Qué cómic o novela gráfica has leído recientemente que refleje temas socialmente 
relevantes? ¿Qué tipo de novela gráfica prefieres? ¿Estás en contacto con otros historietistas españoles o extranjeros contemporáneos? ¿Tienes un autor $o$ autora favorita de cómics?

Recientemente he leído el último libro del autor francés Jean-Christophe Menu, que se llama Chroquettes (Fluide Glacial, 2016). Menu es uno de mis autores preferidos y el autor de uno de los mejores libros teóricos sobre cómics, La Bande dessinée et son double (L'Association, 2011). También he leído Fun (Coconino Press, 2014), de Paolo Bacilieri, que es muy memorable. Me gustan los clásicos, por ejemplo, Corto Maltese. Una ballata del mare salato (1967) de Hugo Pratt o Trazo de tiza (1993) de Miguelanxo Pra- do. Obras excepcionales. Es muy recomendable El arte de volar (Edicions de Ponent, 2009) de Altarriba y Kim. También me gustan las series Paracuellos de Carlos Giménez y Valentina de Guido Crepax. He leído con mucho interés la novela gráfica From Hell (1999) de Alan Moore y Eddie Campbell. Estoy en contacto habitual con los colegas de medio mundo pero mi caso es especial porque organizo dos eventos (Semana Negra de Gijón y Jornadas Internacionales del Cómic de Avilés, ambas en España). También suelo acudir a muchos encuentros de autores. Mis favoritos son Hugo Pratt, Guido Crepax, Miguelanxo Prado, Alan Moore, Art Spiegelman y Frank Miller. Pero tengo más autores favoritos. La lista sería muy larga. 